\title{
Archaeointensity Variations for the Past 7,500 Years Evaluated from Ancient Chinese Ceramics
}

\author{
J. SHAW ${ }^{1}, \mathrm{~S} . \mathrm{YANG}^{1}$, and Q. Y. WEI ${ }^{2}$ \\ ${ }^{1}$ Geomagnetism Laboratory, Department of Earth Sciences, The University of Liverpool, L69 3BX, England \\ ${ }^{2}$ Institute of Geophysics, Chinese Academy of Sciences, Beijing 100101, P.R. China
}

(Received December 22, 1993; Revised September 30, 1994; Accepted October 4, 1994)

\begin{abstract}
Archaeointensity data have been obtained for the past 7,500 years by analyzing ancient Chinese ceramics using a new version of the Shaw techniques (Shaw, 1974) and the Coe (1967) version of the Thellier techniques (Thellier and Thellier, 1959). Several rock magnetic parameters and measurements, such as Curie temperature, low temperature susceptibility, hysteresis and magnetic anisotropy, have been made on sub-samples. These measurements have enabled us to preselect the most suitable samples for archaeomagnitude analysis. There is acceptable agreement between the results obtained from separated areas of China. Major features of the geomagnetic field in China determined from this study are generally consistent with those of the global average field model of McElhinny and Senanayake (1982) but with detailed differences which we may be due either to local non-dipole field effects or lack of resolution in the global model. Comparison of the present results with contemporaneous results from Greece (Aitken et al., 1989) shows significant differences that may be due to the movement of a large non-dipole anomaly. Samples younger than 4,000 years ago were usually dated by archaeological context and/or artefact type; radiocarbon dating was used to date the older samples.
\end{abstract}

\section{Introduction}

China, with a long and well-documented history, provides a wealth of archaeomagnetic materials with board geographical and temporal distributions. Since the early 1980s many archaeomagnetic investigations have been carried out (Wei et al., 1982, 1986, 1987; Tang et al., 1991; Yang et al., 1993a, b) and results have been obtained from various artifacts (bricks, tiles, ceramics, baked earth, etc). The ceramic samples used for the present investigation were collected from 10 archaeological areas in north central China and 11 archaeological areas in northeast (NE) China covering 7500 to 900 years ago (Fig. 1 and Table 1). Cylindrical samples with diameter $9 \mathrm{~mm}$ and approximate length 7-10 $\mathrm{mm}$ were used in rock magnetic investigations and in both the Thellier and Shaw techniques. The shape anisotropy caused by different lengths is generally considered to be insignificant in comparison to the intrinsic anisotropy of the samples (Yang et al., 1993a, b).

\section{Magnetic Mineralogy}

A series of experiments has been undertaken to investigate various aspects of the magnetic mineralogy of the ceramics. The magnetic mineralogy of these samples is dominated, in terms of the intensity of magnetisation, by magnetite-type minerals. Since Curie temperature depends only on the type of magnetic mineral the thermomagnetic behaviour of each sample was investigated by measuring the magnetisation of a crushed sub-specimen in a strong field (about 0.6 Tesla) during thermal cycling from room temperature to $700^{\circ} \mathrm{C}$ and back to room temperature in air. The Curie temperatures for these samples are typical of magnetite $\left(570-590^{\circ} \mathrm{C}\right.$, Fig. 2a). The presence 

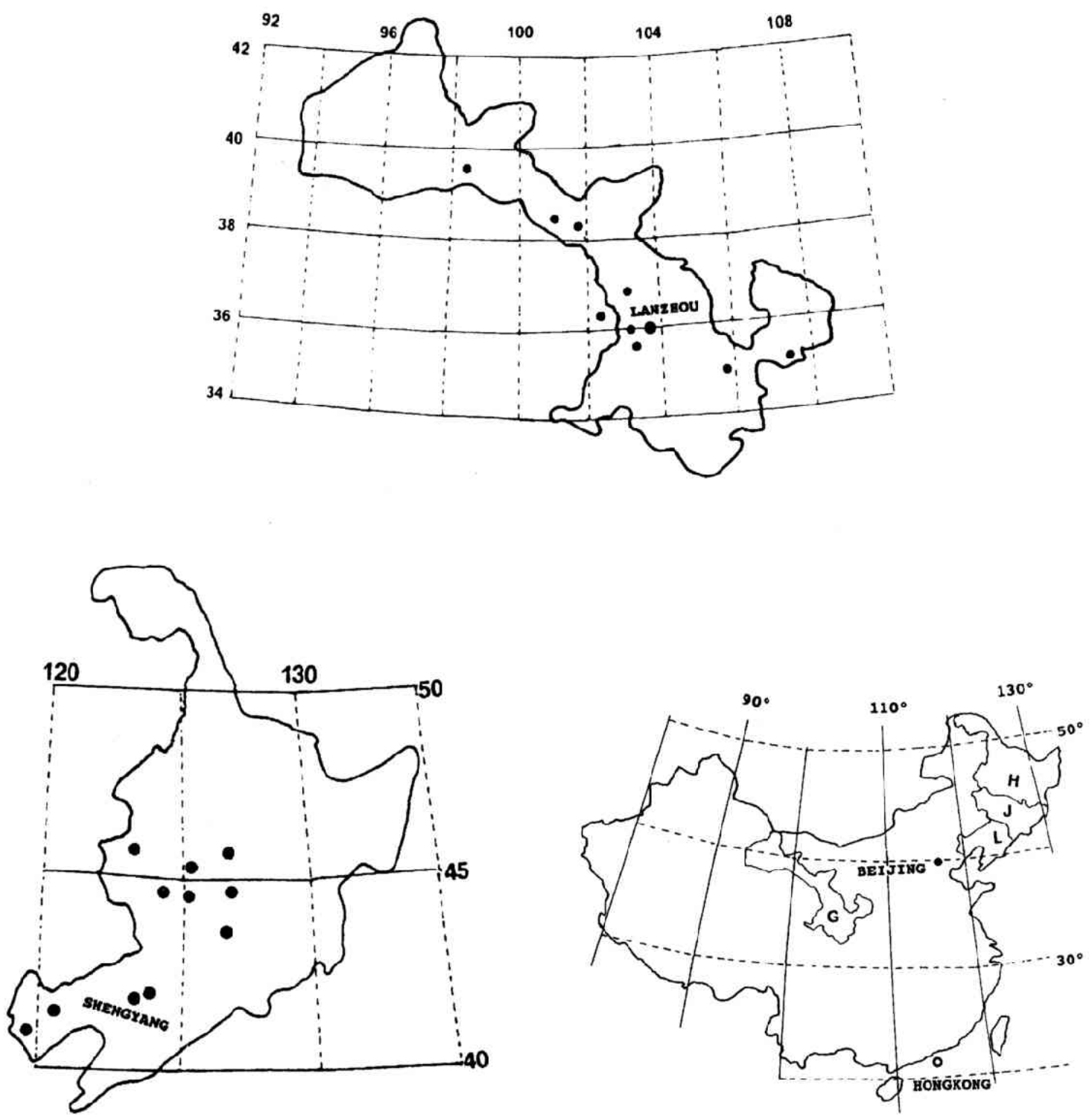

Fig. 1. Distribution of Sampling areas in north central and northeast China. G, H, J, and L are the abbreviations of Gansu, Helongjiang, Jilin and Liaolin provinces respectively.

of cation deficient (CD) magnetite was identified for some samples with Curie temperatures distributed in the range of $610-630^{\circ} \mathrm{C}$ (Fig. 2b). The apparent absence of haematite (Curie temperature $680^{\circ} \mathrm{C}$ ) may simply reflect its relatively weak saturation magnetisation, which is about two orders at magnitude less than magnetite. Thus when a significant portion of magnetite is present, the signal from haematite is swamped.

The precise nature and size distribution of domain states cannot be elucidated. However, using the ratio Mrs/Ms (Fig. 3) from magnetic hysteresis results together with susceptibility changes from liquid nitrogen temperature $\left(-196^{\circ} \mathrm{C}\right)$ to room temperature, some information about the domain states can be estimated. If the magnetic mineral in a sample is only magnetite, 
Table 1. Site mean archaeointensity data from Chinese Ceramics.

\begin{tabular}{|c|c|c|c|c|c|c|c|}
\hline Site & Lat & Long & Dynasty & Age (B.P.) & Method & $\mathrm{N}$ & $\mathrm{Ba} \pm \mathrm{Sd}$ \\
\hline ShenYang & $41.75^{\circ}$ & $123.4^{\circ}$ & Neolithic & $7000 \pm 500$ & C14 & 2 & $36.2 \pm 5.9$ \\
\hline LongAn & $44.5^{\circ}$ & $125.2^{\circ}$ & Neolithic & $6500 \pm 500$ & C14 & 1 & $36.9 \pm 5.6$ \\
\hline ChangLing & $44.6^{\circ}$ & $124.0^{\circ}$ & Neolithic & $6000 \pm 500$ & C14 & 1 & $31.9 \pm 4.6$ \\
\hline ZhengGun & $44.8^{\circ}$ & $123.2^{\circ}$ & Neolithic & $4750 \pm 450$ & C14 & 2 & $37.0 \pm 4.5$ \\
\hline ShenYang & $41.75^{\circ}$ & $123.4^{\circ}$ & Neolithic & $4500 \pm 400$ & C14 & 4 & $41.8 \pm 1.2$ \\
\hline ChangLing & $44.6^{\circ}$ & $124.0^{\circ}$ & Neolithic & $4200 \pm 300$ & C14 & 1 & $45.1 \pm 3.7$ \\
\hline ChaoYang & $41.6^{\circ}$ & $120.5^{\circ}$ & Xia & $3750 \pm 250$ & $\mathrm{~A}^{*}$ & 2 & $67.2 \pm 4.1$ \\
\hline ChaoYang & $41.6^{\circ}$ & $120.5^{\circ}$ & Early Shany & $3500 \pm 200$ & $\mathrm{~A}^{*}$ & 1 & $59.2 \pm 2.6$ \\
\hline FuShun & $41.8^{\circ}$ & $123.9^{\circ}$ & Late Shang & $3150 \pm 200$ & $\mathrm{~A}^{*}$ & 2 & $64.6 \pm 2.5$ \\
\hline GeZho & $41.0^{\circ}$ & $119.7^{\circ}$ & Shang-Zhou & $3000 \pm 250$ & $\mathrm{~A}^{*}$ & 2 & $53.7 \pm 2.2$ \\
\hline ChaoYang & $41.6^{\circ}$ & $120.5^{\circ}$ & Western Zhou & $2763 \pm 200$ & $\mathrm{~A}^{*}$ & 3 & $55.8 \pm 5.0$ \\
\hline ZhaoYuan & $45.4^{\circ}$ & $125.1^{\circ}$ & Western Zhou & $2750 \pm 150$ & $\mathrm{~A}^{*}$ & 2 & $52.8 \pm 6.2$ \\
\hline FuShun & $41.8^{\circ}$ & $123.9^{\circ}$ & Western Zhou & $2550 \pm 300$ & $\mathrm{~A}^{*}$ & 2 & $48.2 \pm 3.8$ \\
\hline YongJi & $43.65^{\circ}$ & $126.5^{\circ}$ & Western Zhou & $2500 \pm 300$ & $\mathrm{~A}^{*}$ & 2 & $54.1 \pm 0.2$ \\
\hline YuShu & $44.85^{\circ}$ & $126.5^{\circ}$ & Western Han & $1990 \pm 150$ & $\mathrm{~A}^{*}$ & 1 & $56.4 \pm 4.0$ \\
\hline FuShun & $41.8^{\circ}$ & $123.9^{\circ}$ & Eastern Han & $1870 \pm 98$ & $\mathrm{~A}^{*}$ & 2 & $56.6 \pm 0.2$ \\
\hline ChaoYang & $41.6^{\circ}$ & $120.5^{\circ}$ & Eastern Han & $1770 \pm 198$ & $\mathrm{~A}^{*}$ & 2 & $55.2 \pm 1.7$ \\
\hline ChaoYang & $41.6^{\circ}$ & $120.5^{\circ}$ & Liao & $976 \pm 109$ & $\mathrm{~A}^{*}$ & 5 & $64.1 \pm 4.5$ \\
\hline A'Cheng & $45.6^{\circ}$ & $126.9^{\circ}$ & Liao & $900 \pm 100$ & $\mathrm{~A}^{*}$ & 1 & $64.1 \pm 6.3$ \\
\hline DongXiang & $35.9^{\circ}$ & $103.5^{\circ}$ & Neolithic & $4750 \pm 300$ & C14 & 3 & $29.1 \pm 3.0$ \\
\hline LanZhou & $36.0^{\circ}$ & $103.8^{\circ}$ & Neolithic & $4000 \pm 400$ & C14 & 2 & $46.5 \pm 1.0$ \\
\hline LeDou & $36.3^{\circ}$ & $102.4^{\circ}$ & Neolithic & $7000 \pm 700$ & C14 & 3 & $34.6 \pm 2.8$ \\
\hline LingTai & $35.1^{\circ}$ & $107.6^{\circ}$ & Xia-Shany & $3700 \pm 350$ & $\mathrm{~A}^{*}$ & 2 & $46.9 \pm 3.5$ \\
\hline MinLe & $38.5^{\circ}$ & $101.1^{\circ}$ & Xia-Shany & $3500 \pm 350$ & $\mathrm{~A}^{*}$ & 2 & $44.0 \pm 2.5$ \\
\hline Qin'an & $34.8^{\circ}$ & $105.7^{\circ}$ & Neolithic & $7500 \pm 600$ & C14 & 3 & $30.8 \pm 0.4$ \\
\hline Qin'an & $34.8^{\circ}$ & $105.7^{\circ}$ & Neolithic & $6200 \pm 500$ & C14 & 3 & $27.9 \pm 1.5$ \\
\hline Qin'an & $34.8^{\circ}$ & $105.7^{\circ}$ & Neolithic & $5000 \pm 350$ & C14 & 2 & $36.6 \pm 2.7$ \\
\hline Qin'an & $34.8^{\circ}$ & $105.7^{\circ}$ & Neolithic & $5700 \pm 350$ & C14 & 3 & $28.7 \pm 1.0$ \\
\hline Qin'an & $34.8^{\circ}$ & $105.7^{\circ}$ & Neolithic & $5200 \pm 400$ & C14 & 2 & $35.6 \pm 0.5$ \\
\hline YongDeng & $36.8^{\circ}$ & $103.3^{\circ}$ & Western Zhou & $2700 \pm 150$ & $\mathrm{~A}^{*}$ & 2 & $42.1 \pm 6.0$ \\
\hline YongCheng & $38.2^{\circ}$ & $101.9^{\circ}$ & Neolithic & $4500 \pm 350$ & C14 & 3 & $40.0 \pm 2.1$ \\
\hline YongQing & $35.7^{\circ}$ & $103.3^{\circ}$ & Xiao-Shang & $3600 \pm 350$ & C14 & 3 & $49.5 \pm 6.8$ \\
\hline
\end{tabular}

$A^{*}$ : Dating was made by archaeological context and/or artefact type.

the value of Mrs/Ms can give an insight into the distribution of domain states (Day et al., 1977), e.g. 0.5 for single-domain (SD), from 0.5 to 0.1 for pseudo-single-domain (PSD), less than 0.1 for multidomain (MD) and even lower for superparamagnetic (SP) grains. It was found that superparamagnetic (SP) and single domain (SD) particles dominate the magnetic mineralogy of most samples, although the presence of MD particles is evident for a few samples which showed susceptibility peaks at about $-150^{\circ} \mathrm{C}$ (Senanayake and McElhinny, 1981).

The mineralogy and domain states of the magnetic particles present in a ceramic shard affect the acquisition of the NRM, the alteration of the NRM over time and the retrieval of the ancient field magnitude from the ceramic sample. Samples containing CD magnetite are problematic since CD magnetite is a low temperature alteration product of magnetite and part of the remanence held by CD magnetite is probably formed chemically after the initial firing.

The anisotropy of magnetic susceptibility (AMS) caused by a preferred orientation of magnetic particles and the effect of AMS upon TRM and ARM acquisition is a well known phe- 

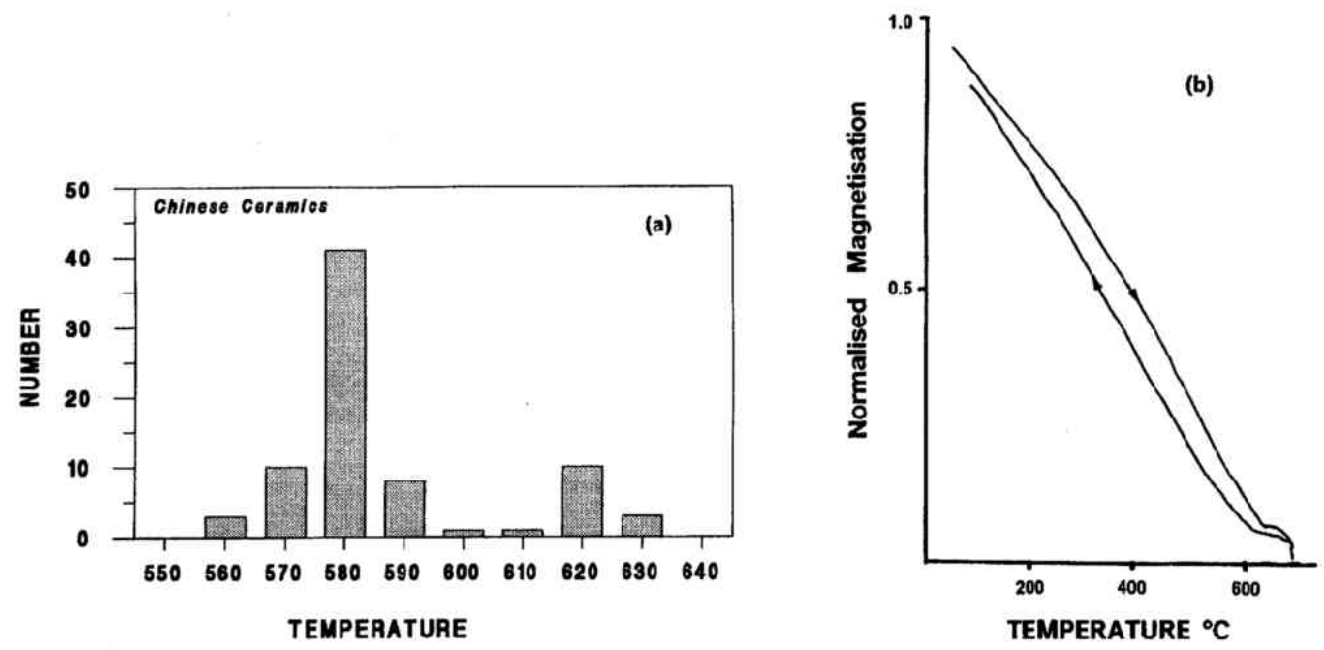

Fig. 2. (a) Histogram of Curie temperatures for a collection of pottery samples from north central and northeast China. (b) An example of a thermomagnetic curves showing Curie temperatures higher than $600^{\circ} \mathrm{C}$.

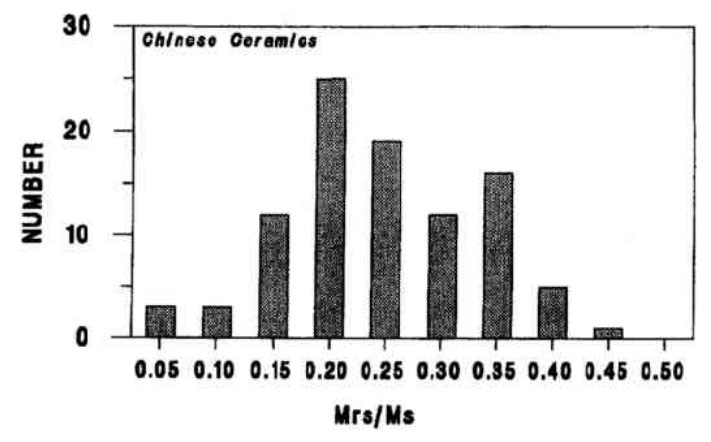

Fig. 3. Histogram of Mrs/Ms of a collection of pottery samples from north central and northeast China.

nomenon that has been investigated previously (Rogers et al., 1979; Stephenson et al., 1986; Yang et al., 1993a). The direction and normalised magnitudes of the susceptibility axes ( $K 1$, $K 2, K 3$, where $K 1>K 2>K 3$ ) were measured for all the samples using a Molspin anisotropy delineator. These AMS measurements showed that the orientation of the minimum axis $(K 3)$ is nearly perpendicular to the plane of the ceramics and $K 1$ and $K 2$ (which define an 'easy plane' of magnetisation) are almost coincident with the plane of the ceramics. Samples showed quite a high degree of anisotropy, with an average $K 1 / K 3$ of about 1.1. The anisotropy ratio of remanence (TRM or ARM) is even greater. In archaeointensity studies, the direction of the TRM produced in the laboratory (in our experiments usually along the axes of the cylindrical samples) often differs from the direction of the NRM. In such circumstances an anisotropy correction should be applied otherwise the archaeointensity will be overestimated (Yang et al., 1993a). 


\section{Archaeointensity Determinations}

For the samples from north central China, 20 of them were analyzed using the Shaw method and 34 using the Thellier method. Acceptable agreement between the results from two method was found (Yang et al., 1993a). A previous investigation of ceramic samples from Peru (Yang et al., 1993c) found that the lower part of the NRM blocking temperature spectrum (up to $300^{\circ} \mathrm{C}$ ) was often affected by magnetic viscosity or partial reheating. Chemical alteration usually occurred during laboratory heating to higher temperatures so it is was sometimes quite difficult to choose a suitable NRM temperature range for archaeointensity determination by the Thellier technique. Although the modified Shaw technique (Rolph and Shaw, 1985) can provide a correc-

SAMPLE CNNE4

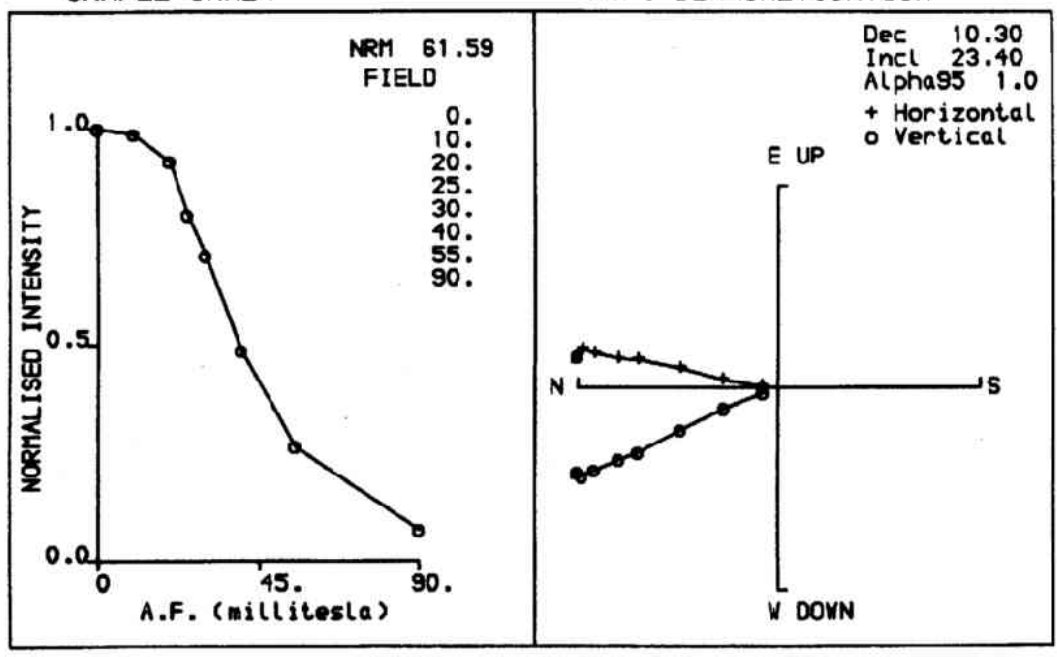

SAMPLE CNNE4

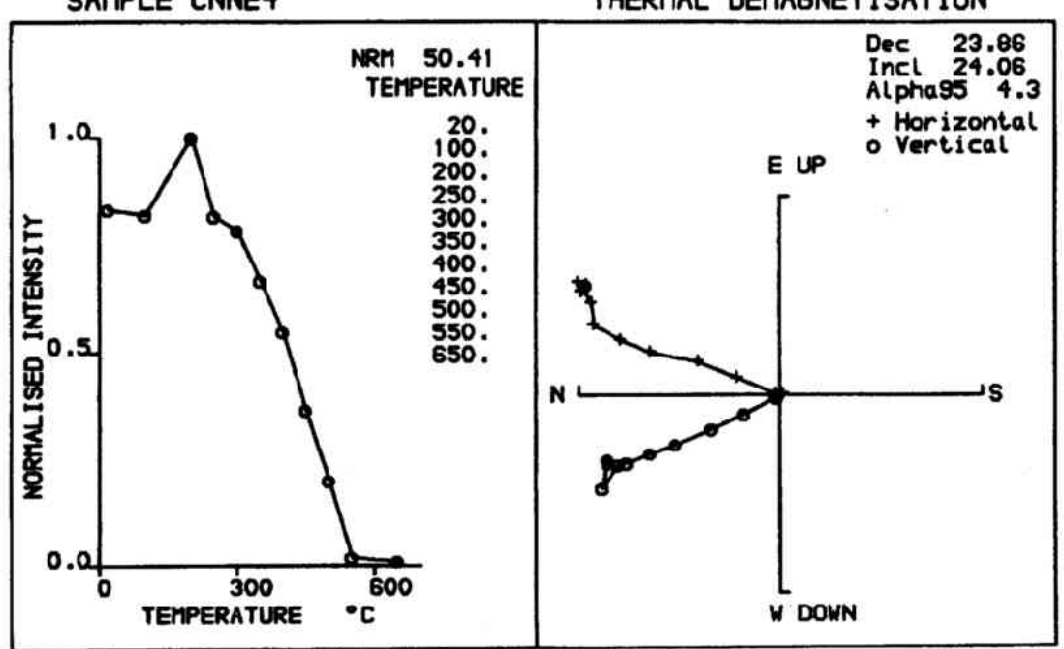

Fig. 4. Examples of thermal and a.f. demagnetisation of NRM. 
tion for thermal alteration by using ARM1 and ARM2 (ARM1 given before, and ARM2 given after a laboratory heating and in identical conditions) to correct the TRM for thermal alteration, alternating field (AF) demagnetisation was not always able to isolate the low temperature PTRM components that had been identified in samples by thermal demagnetisation (Yang et al., 1993a). In an attempt to incorporate the best aspects of the Thellier and Shaw techniques the samples from northeast China were initially thermally demagnetized to $300^{\circ} \mathrm{C}$ and then the remaining remanences (NRM, ARM1, TRM, ARM2) were analyzed by AF demagnetisation, as in the modified Shaw palaeointensity technique (Rolph and Shaw, 1985). The palaeointensity experimental procedures consisted of the following steps.

(1) Measure the total NRM for each sample.

(2) Heat the sample to $100^{\circ} \mathrm{C}$ in zero magnetic field and measure the NRM remaining.

(3) Heat the sample to $100^{\circ} \mathrm{C}$ and cool in a magnetic field of $50 \mu \mathrm{T}$ to create PTRM1; measure PTRM1.

(4) Thermally demagnetise by heating to $300^{\circ} \mathrm{C}$ in a zero field and then measure the NRM remaining.

(5) Heat the sample to $100^{\circ} \mathrm{C}$ and cool in a magnetic field of $50 \mu \mathrm{T}$ to create PTRM2; measure PTRM2.

(6) Thermally demagnetise by heating to $100^{\circ} \mathrm{C}$ and cool in a zero magnetic field.

(7) Stepwise AF demagnetise and measure up to $170 \mathrm{mT}$.

(8) Create an ARM (ARM1) in the same direction as the NRM.

(9) Thermally demagnetise to $300^{\circ} \mathrm{C}$ and then stepwise AF demagnetise and measure PARM1 as in (7).

(10) Heat to $650^{\circ} \mathrm{C}$ and cool in a field of $50 \mu \mathrm{T}$ to create a TRM.

(11) Thermally and AF demagnetise as in (9).

(12) Create ARM2 in the same direction as the TRM.

(13) Thermally and AF demagnetise as in (9).

\section{SAMPLE CNNE4}

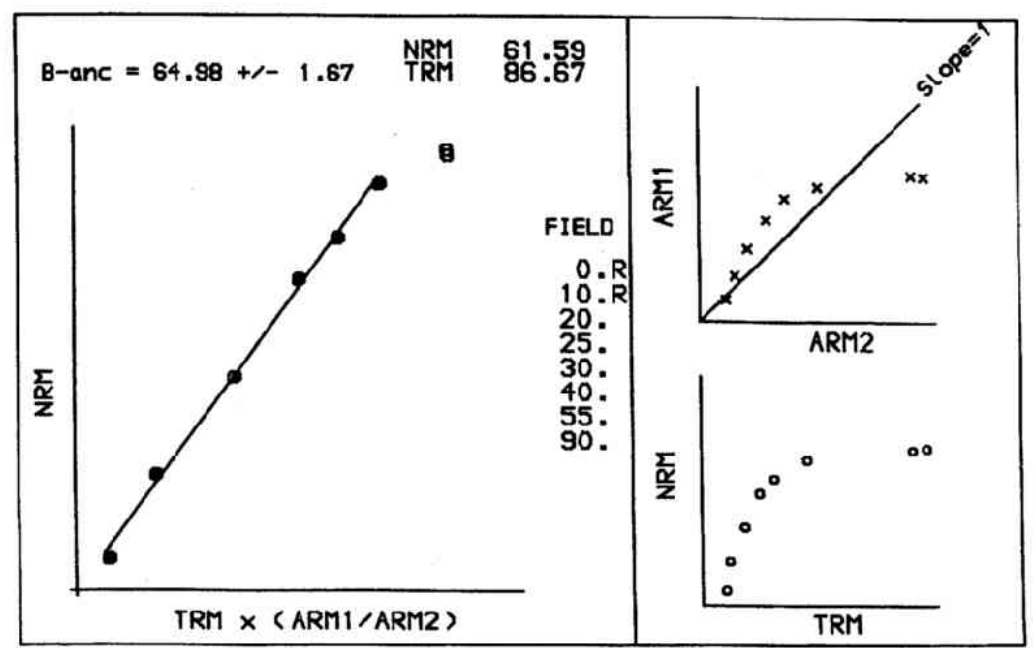

Fig. 5. An example of archaeointensity determination by the modified Shaw Method. NRM, TRM, ARM1 and ARM2 are partial remanences from the blocking temperature interval above $300^{\circ} \mathrm{C}$ rather than total remanences. The units for archaeointensity are $\mu \mathrm{T}$, the units for NRM and TRM are $10^{-5} \mathrm{Am}^{2} \mathrm{~kg}^{-1}$. 
By comparing PTRM1 and PTRM2 for each sample, thermal alteration can be checked in the intervening heating steps. For the samples showing a significant difference between the PTRMs, the magnetic susceptibility or thermomagnetic behaviour is used to confirm the chemical alteration. Four samples were rejected because the magnetic susceptibility also showed significant alteration (more than $5 \%$ ) after heating to $300^{\circ} \mathrm{C}$.

A previous investigation (Yang et al., 1993a) demonstrated that ARM anisotropy is very similar to the corresponding TRM anisotropy and therefore ARM can be used to replace TRM for anisotropy correction when using the Thellier technique. When using the Shaw technique in the present investigation, ARM1 and ARM2 were given in the direction of the NRM and TRM respectively. The ARM correction (Rolph and Shaw, 1985) was applied to the TRM; this also corrects for any magnetic anisotropy. It was found that the ARM-corrected TRM (TRMc), as shown in an example in Figs. 4 and 5, often shows a linear NRM-TRMc relationship although the NRM-TRM relationship deviates from a straight line.

To impart the TRM's used in experiments, samples were cooled down from elevated temperature to room temperature in about half an hour, almost two orders of magnitude faster than the cooling which took place in antiquity. Experimental results indicate that such disparity in cooling rates can cause archaeointensities to be overestimated up to $10 \%$ (Fox and Aitken, 1980). To observe this cooling rate effect, fifteen samples were given consecutive TRMs, the first with a cooling time of 35 minutes and the second with a cooling time of 7 hours. The slower cooled TRMs compared to the faster cooled TRM's showed a an average increase of $4 \%$ (1\% to $6 \%$ for individual sample), as shown in Fig. 6. However no cooling rate correction has been applied to the results presented here. The archaeointensity results from the present investigation are given in Table 1 and the specimen data are summarized in the Appendix. There is good agreement between the results from north central China and northeast China, as shown in Fig. 7.

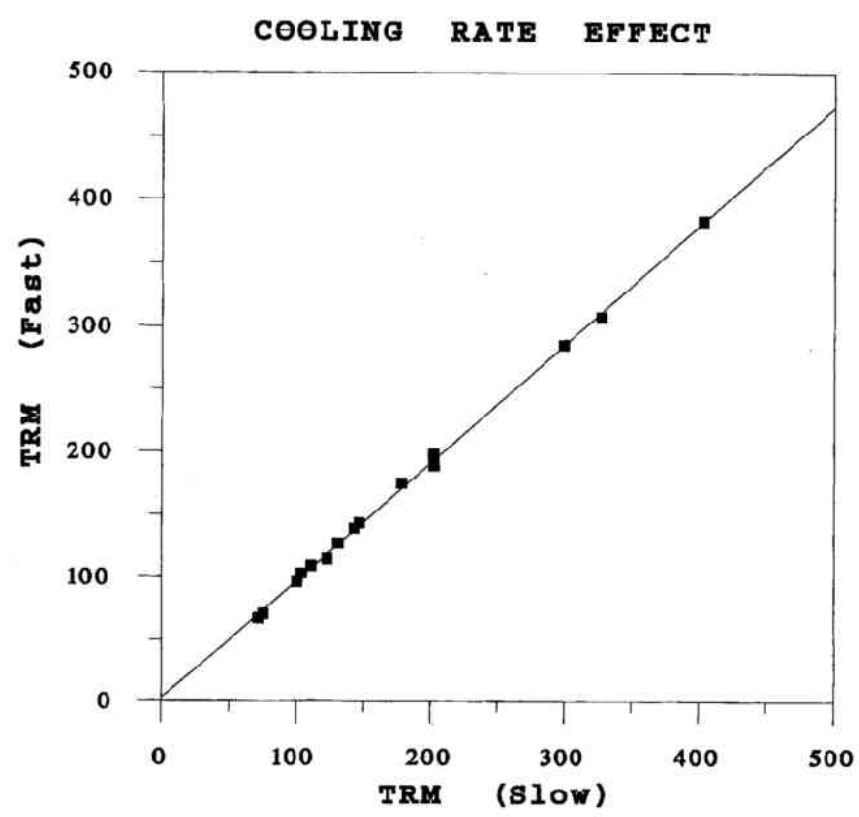

Fig. 6. TRM's of 15 Chinese ceramics obtained by cooling from $650^{\circ} \mathrm{C}$ in a constant laboratory field (50 $\mu \mathrm{T}$ ) with cooling time of about 35 minutes (fast) or 7 hours (slow). The line was fitted by least squares regression and has a slope of 0.94 . The units for TRM are $10^{-5} \mathrm{Am}^{2} \mathrm{~kg}^{-1}$. 


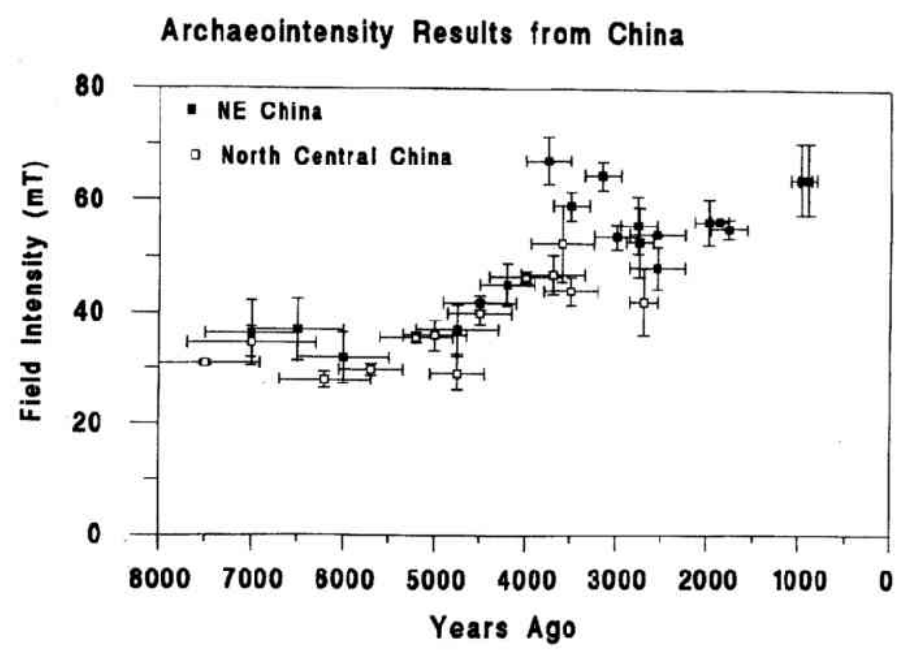

Fig. 7. Archaeointensity results from north central and northeast China.

\section{Discussion and Conclusion}

The equivalent virtual axial dipole moments (VDAM) of the archaeointensity results from northeast China and a smoothed secular variation curve, fitted by using a cubic spline approximation in which the error of each data point (the standard error of the mean) was used as a weighting factor, are shown in Fig. 8. After an initial small decrease $\left(6.5 \times 10^{22} \mathrm{Am}^{2}\right.$ to $6.0 \times 10^{22} \mathrm{Am}^{2}$, $7500-5500$ years ago $)$ the dipole moment shows a large increase almost doubling $\left(6.0 \times 10^{22} \mathrm{Am}^{2}\right.$ to $11.0 \times 10^{22} \mathrm{Am}^{2}$ ) between 5500 and 3500 years ago. Thus it forms a peak at about 3500 years ago. The magnitude of the VADM decreased for about 1000 years, from 3500 years ago to 2500 years ago, (from 11.0 to $8.5 \times 10^{22} \mathrm{Am}^{2}$ or even lower). This decrease can also be seen in previous archaeointensity results from different areas of China (Wei et al., 1982, 1986, 1987), as shown in Fig. 9, but cannot be clearly identified in the global model of McElhinny and Senanayake (1982). Comparing our Chinese data with Japanese data (Tanaka, 1990), it is found that generally the changes in the magnitude of the geomagnetic field are very similar for the past 2,000 years. Some anomalously high values are found in the Japanese data around 3,000-4,000 years ago, but they do not form a clear peak in paleointensity. Using the Thellier method on Hawaiian volcanics, palaeointensity results for the last 15,000 years were recently reported (Mankinen and Champion, 1993) with some high palaeointensity values around 3,000-4,000 years ago. High values in the Chinese, Japanese and Hawaii results suggest a global high palaeointensity value around 3,500 years ago.

Alternatively the Chinese 3,500 year maximum may be a local feature of the non-dipole field. Geomagnetic intensity variations from Greece for the last 4000 years (Aitken et al., 1989) show a maximum close to 2,650 years ago and a minimum at about 1800 years ago. This decrease lags significantly behind the equivalent trend in the Chinese results which may indicate that it is not dipolar in origin. In order to look at the non-dipole field in Greece and China each archaeomagnetic data set was first normalised to its average and then subtracted from the similarly normalised global field model of McElhinny and Senanayake (1982). If the observed decrease in field strength is attributed to a non-dipole source then it is possible to determine the sense and rate of the drift of this feature by comparing the two data sets. This analysis indicates a westward drift (Fig. 10) of a non-dipole feature. The magnitude of the supposed non-dipole fields are as 


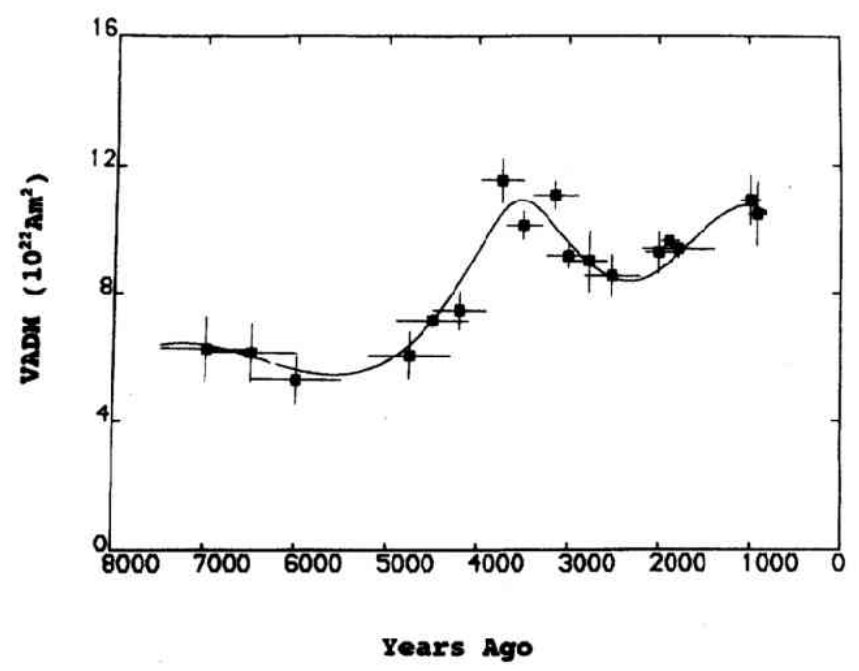

Fig. 8. The results from northeast China averaged according to age. Vertical error bars are the standard error of the mean. The curve is a cubic spline approximation.

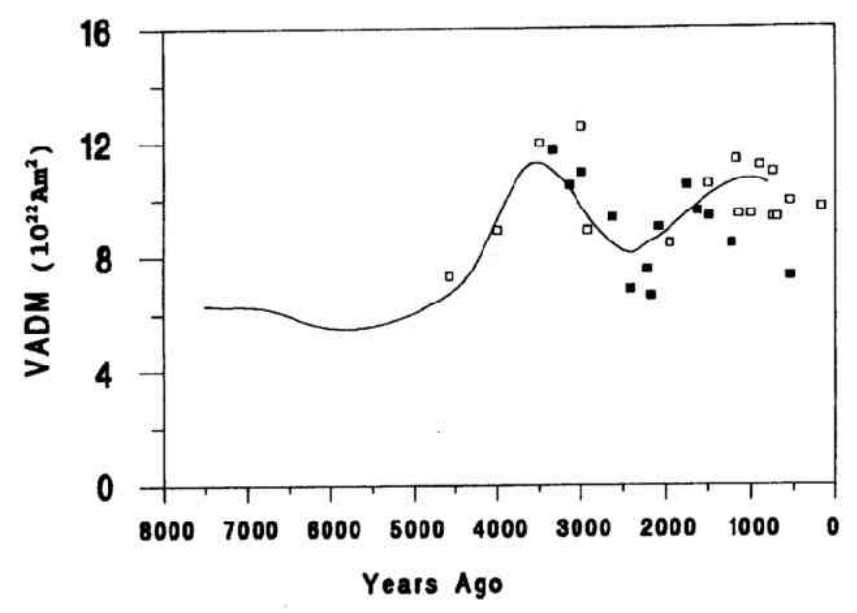

Fig. 9. Comparison of present results from northeast China (curve) with previous archaeointensity data from central east China (square) and south east China (solid square) (after Wei et al., 1982, 1986, 1987).

high as $26 \%$ of the dipole field in China but only $17 \%$ or less in Greece. Using cross correlation analysis, the Greek curve lags the Chinese curve by 800 years (cross correlation coefficient 0.87 ). If we consider the average longitude of the two sites (Greece, $23^{\circ} \mathrm{E}$; NE China $124^{\circ} \mathrm{E}$ ), the rate of westward drift of this large non-dipole anomaly is estimated to be about $0.126^{\circ} / \mathrm{yr}$. This westward drift rate is within the limits $\left(0.1-0.4^{\circ} / \mathrm{yr}\right)$ derived by Aitken et al. (1989) and also consistent with the value of $0.2^{\circ} / \mathrm{yr}$ derived by Bullard et al. (1950). The two archaeomagnetic curves (Fig. 10) corrected for westward drift are not identical but that is to be expected because non-dipole anomalies are themselves changing shape and magnitude with time and the global model of McElhinny and Senanayake (1982) contains more weighing for European results. Also 


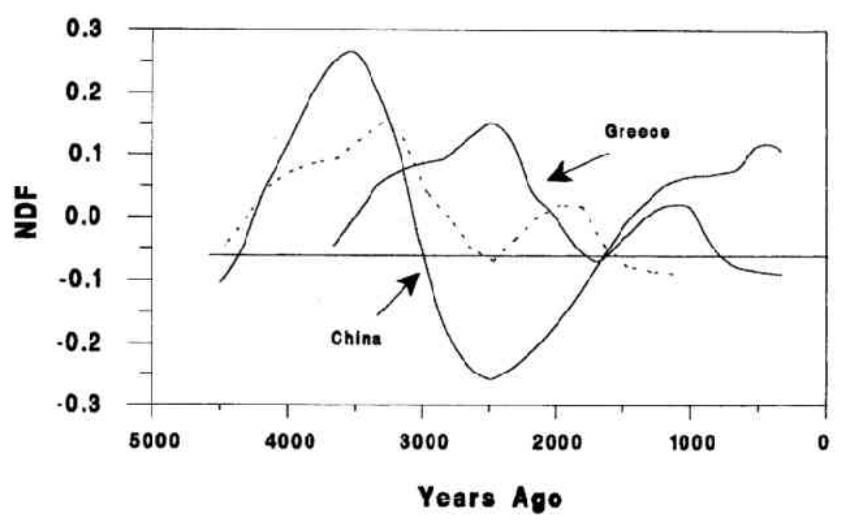

Fig. 10. Comparison of normalised NDF (non-dipole Field) intensities expressed as the difference between normalised archaeointensity data and the normalised dipole field data of McElhinny and Senanayake (1982). Present result from northeast China and Greece (solid curves as indicated separately) and Greece with time shifted 800 years (dashed curve).

the peak VDM for north central China is lower in magnitude than the peak for northeast China (Fig. 7). The average latitude difference between the two data sets is $10^{\circ}$ so this difference may be because the north central China sites are on the southern flanks of a non-dipole anomaly while the northeast sites are nearer the centre of the anomaly.

Is the 3,500 year maximum a global or local feature? Better regional and global coverage of archaeointensity results is necessary if we are to answer this important question.

We would like to thank the University of Liverpool for supporting S. Yang on a university postgraduate studentship and the Institute of Geophysics, Beijing, who helped with the collection of samples. Our thanks also go to H. Tsunakawa and E. Schnepp for their helpful comments and suggestions. J. Shaw acknowledges support from the British Council.

Appendix: Specimen Data

\begin{tabular}{lclccccccc}
\hline \multicolumn{1}{c}{ Site } & Sample & Method & $\mathrm{Bl}(\mu \mathrm{T})$ & Low-High & $\mathrm{n}$ & $-\mathrm{r}$ & -b & Ba \pm Sd & Age (B.P) \\
\hline ShenYang & A & Shaw & 50 & $20-110$ & 7 & 0.996 & 0.853 & $42.6 \pm 1.4$ & $7000 \pm 500$ \\
& $\mathrm{~B}$ & Shaw & 50 & $20-110$ & 7 & 0.998 & 0.612 & $30.2 \pm 1.2$ & \\
LongAn & $\mathrm{A}$ & Shaw & 50 & $30-140$ & 7 & 0.984 & 0.737 & $36.9 \pm 5.6$ & $6500 \pm 500$ \\
ChangLing & $\mathrm{A}$ & Shaw & 50 & $20-110$ & 7 & 0.989 & 0.638 & $31.9 \pm 4.6$ & $6000 \pm 500$ \\
ZhengGun & $\mathrm{A}$ & Shaw & 50 & $20-110$ & 7 & 0.967 & 0.762 & $38.1 \pm 9.7$ & $4750 \pm 450$ \\
& $\mathrm{~B}$ & Shaw & 50 & $20-110$ & 7 & 0.992 & 0.728 & $36.4 \pm 4.5$ & \\
ShenYang & A & Shaw & 50 & $30-110$ & 6 & 0.999 & 0.856 & $42.8 \pm 1.7$ & $4500 \pm 400$ \\
& B & Shaw & 50 & $30-110$ & 6 & 0.999 & 0.892 & $44.6 \pm 2.7$ & \\
& C & Shaw & 50 & $30-110$ & 6 & 0.997 & 0.828 & $41.4 \pm 4.9$ & \\
ChangLing & D & Thellier & 50 & $250-550$ & 7 & 0.994 & 0.836 & $41.8 \pm 3.3$ & \\
ChaoYang & A & Shaw & 50 & $20-140$ & 8 & 0.997 & 0.902 & $45.1 \pm 3.7$ & $4200 \pm 300$ \\
& Shaw & 50 & $10-160$ & 8 & 0.998 & 1.424 & $71.2 \pm 3.4$ & $3750 \pm 250$ \\
ChaoYang & A & Shaw & 50 & $10-160$ & 8 & 0.993 & 1.274 & $63.7 \pm 4.1$ & \\
FuShun & Shaw & 50 & $20-110$ & 7 & 0.995 & 1.184 & $59.2 \pm 2.6$ & $3500 \pm 200$ \\
& B & Shaw & 50 & $10-90$ & 7 & 0.991 & 1.344 & $67.2 \pm 2.1$ & $3150 \pm 200$
\end{tabular}




\begin{tabular}{|c|c|c|c|c|c|c|c|c|c|}
\hline \multirow[t]{2}{*}{ GeZho } & A & Thellier & 50 & $200-500$ & 7 & 0.982 & 1.012 & $50.6 \pm 5.8$ & $3000 \pm 250$ \\
\hline & B & Shaw & 50 & $0-70$ & 9 & 0.999 & 1.114 & $55.9 \pm 1.7$ & \\
\hline \multirow[t]{3}{*}{ ChaoYang } & A & Shaw & 50 & $20-110$ & 7 & 0.996 & 1.192 & $59.6 \pm 3.9$ & $2763 \pm 200$ \\
\hline & B & Shaw & 50 & $20-110$ & 7 & 0.991 & 0.966 & $48.3 \pm 3.2$ & \\
\hline & $\mathrm{C}$ & Thellier & 50 & $200-500$ & 7 & 0.986 & 1.192 & $59.6 \pm 5.6$ & \\
\hline \multirow[t]{2}{*}{ ZhaoYuan } & A & Shaw & 50 & $20-110$ & 7 & 0.989 & 1.072 & $53.6 \pm 5.9$ & $2750 \pm 150$ \\
\hline & B & Shaw & 50 & $20-110$ & 7 & 0.990 & 1.040 & $52.0 \pm 6.2$ & \\
\hline \multirow[t]{2}{*}{ FuShun } & A & Shaw & 50 & $35-140$ & 6 & 0.992 & 0.966 & $48.3 \pm 3.3$ & $2550 \pm 300$ \\
\hline & B & Shaw & 50 & $35-140$ & 6 & 0.990 & 0.962 & $48.1 \pm 3.8$ & \\
\hline \multirow[t]{2}{*}{ YongJi } & $\mathrm{A}$ & Shaw & 50 & $30-140$ & 6 & 0.992 & 1.072 & $53.8 \pm 4.6$ & $2500 \pm 300$ \\
\hline & B & Shaw & 50 & $30-140$ & 6 & 0.973 & 1.086 & $54.3 \pm 9.2$ & \\
\hline YuShu & A & Shaw & 50 & $20-130$ & 7 & 0.991 & 1.128 & $56.4 \pm 4.0$ & $1990 \pm 150$ \\
\hline \multirow[t]{2}{*}{ FuShun } & A & Shaw & 50 & $30-140$ & 6 & 0.994 & 1.128 & $56.4 \pm 3.0$ & $1870 \pm 98$ \\
\hline & B & Shaw & 50 & $30-140$ & 6 & 0.999 & 1.136 & $56.8 \pm 1.8$ & \\
\hline \multirow[t]{2}{*}{ ChaoYang } & $\mathrm{A}$ & Shaw & 50 & $10-80$ & 6 & 0.986 & 1.136 & $56.8 \pm 5.1$ & $1770 \pm 198$ \\
\hline & B & Shaw & 50 & $10-80$ & 6 & 0.997 & 1.014 & $50.7 \pm 2.0$ & \\
\hline \multirow[t]{5}{*}{ ChaoYang } & $\mathrm{A}$ & Shaw & 50 & $20-90$ & 6 & 0.999 & 1.301 & $65.0 \pm 1.7$ & $976 \pm 109$ \\
\hline & B & Shaw & 50 & $20-90$ & 6 & 0.992 & 1.366 & $68.3 \pm 3.3$ & \\
\hline & $\mathrm{C}$ & Thellier & 50 & $200-500$ & 7 & 0.994 & 1.314 & $65.7 \pm 2.2$ & \\
\hline & $\mathrm{D}$ & Shaw & 50 & $20-110$ & 7 & 0.990 & 1.172 & $58.6 \pm 4.4$ & \\
\hline & $\mathrm{E}$ & Shaw & 50 & $20-110$ & 7 & 0.997 & 1.390 & $69.5 \pm 3.3$ & \\
\hline A'Cheng & $\bar{A}$ & Thellier & 50 & $200-500$ & 7 & 0.983 & 1.282 & $64.1 \pm 6.3$ & $900 \pm 100$ \\
\hline \multirow[t]{3}{*}{ DongXiang } & $\mathrm{A}$ & Thellier & 50 & $250-550$ & 7 & 0.987 & 0.588 & $29.4 \pm 3.1$ & $4750 \pm 300$ \\
\hline & B & Thellier & 50 & $250-550$ & 7 & 0.983 & 0.570 & $28.5 \pm 3.3$ & \\
\hline & $\mathrm{C}$ & Thellier & 50 & $250-550$ & 7 & 0.984 & 0.586 & $29.3 \pm 2.9$ & \\
\hline \multirow[t]{3}{*}{ LanZhou } & A & Thellier & 50 & $300-550$ & 6 & 0.989 & 0.922 & $46.1 \pm 3.3$ & $4000 \pm 400$ \\
\hline & A & Shaw & 50 & $20-100$ & 7 & 0.997 & 0.892 & $44.6 \pm 1.6$ & \\
\hline & B & Shaw & 50 & $20-100$ & 7 & 0.994 & 0.951 & $47.5 \pm 2.6$ & \\
\hline \multirow[t]{4}{*}{ LeDou } & A & Thellier & 50 & $300-550$ & 6 & 0.987 & 0.602 & $30.1 \pm 3.0$ & $7000 \pm 700$ \\
\hline & $\mathrm{A}$ & Shaw & 50 & $20-140$ & 8 & 0.984 & 0.694 & $34.7 \pm 3.2$ & \\
\hline & B & Thellier & 50 & $250-550$ & 7 & 0.995 & 0.636 & $31.8 \pm 1.8$ & \\
\hline & $\mathrm{C}$ & Shaw & 50 & $20-140$ & 8 & 0.997 & 0.722 & $36.4 \pm 1.1$ & \\
\hline \multirow[t]{4}{*}{ LingTai } & A & Thellier & 50 & $250-550$ & 7 & 0.984 & 0.882 & $44.1 \pm 4.4$ & $3700 \pm 350$ \\
\hline & A & Shaw & 50 & $15-100$ & 9 & 0.991 & 0.868 & $43.4 \pm 3.5$ & \\
\hline & B & Thellier & 50 & $250-550$ & 7 & 0.979 & 1.061 & $53.0 \pm 5.7$ & \\
\hline & B & Shaw & 50 & $15-100$ & 9 & 0.986 & 1.006 & $50.3 \pm 5.9$ & \\
\hline \multirow[t]{3}{*}{ MinLe } & A & Thellier & 50 & $350-600$ & 6 & 0.990 & 0.844 & $42.2 \pm 2.2$ & $3500 \pm 300$ \\
\hline & A & Shaw & 50 & $15-130$ & 7 & 0.998 & 0.931 & $46.5 \pm 0.8$ & \\
\hline & B & Thellier & 50 & $300-550$ & 6 & 0.987 & 0.872 & $43.6 \pm 4.5$ & \\
\hline Qin'an & A & Thellier & 50 & $300-550$ & 6 & 0.998 & 0.608 & $30.8 \pm 0.4$ & $7500 \pm 600$ \\
\hline \multirow[t]{3}{*}{ Qin'an } & A & Thellier & 50 & $250-500$ & 6 & 0.983 & 0.514 & $25.7 \pm 2.3$ & $6200 \pm 500$ \\
\hline & A & Shaw & 50 & $20-100$ & 7 & 0.985 & 0.668 & $33.4 \pm 3.7$ & \\
\hline & B & Thellier & 50 & $250-500$ & 6 & 0.997 & 0.528 & $26.4 \pm 1.0$ & \\
\hline \multirow[t]{2}{*}{ Qin'an } & $\mathrm{A}$ & Thellier & 50 & $250-500$ & 6 & 0.984 & 0.772 & $38.7 \pm 4.3$ & $5000 \pm 350$ \\
\hline & B & Thellier & 50 & $250-500$ & 6 & 0.986 & 0.666 & $33.3 \pm 3.5$ & \\
\hline \multirow[t]{3}{*}{ Qin'an } & $\mathrm{A}$ & Thellier & 50 & $250-500$ & 6 & 0.989 & 0.576 & $28.9 \pm 3.1$ & $5700 \pm 350$ \\
\hline & B & Thellier & 50 & $250-500$ & 6 & 0.978 & 0.560 & $28.0 \pm 4.8$ & \\
\hline & B & Shaw & 50 & $20-100$ & 7 & 0.991 & 0.656 & $32.8 \pm 2.9$ & \\
\hline \multirow[t]{3}{*}{ Qin'an } & A & Thellier & 50 & $300-550$ & 6 & 0.990 & 0.694 & $34.7 \pm 3.0$ & $5200 \pm 400$ \\
\hline & B & Thellier & 50 & $300-550$ & 6 & 0.998 & 0.644 & $32.2 \pm 1.2$ & \\
\hline & B & Shaw & 50 & $30-100$ & 5 & 0.984 & 0.816 & $40.8 \pm 2.7$ & \\
\hline YongDeng & A & Thellier & 50 & $300-550$ & 6 & 0.988 & 0.952 & $47.6 \pm 5.5$ & $2700 \pm 150$ \\
\hline & B & Thellier & 50 & $300-550$ & 6 & 0.986 & 0.819 & $41.0 \pm 4.2$ & \\
\hline & B & Shaw & 50 & $20-80$ & 7 & 0.992 & 0.644 & $32.2 \pm 1.9$ & \\
\hline
\end{tabular}




\begin{tabular}{llllclllll} 
YongCheng & A & Thellier & 50 & $250-550$ & 7 & 0.997 & 0.689 & $34.5 \pm 1.9$ & $4500 \pm 350$ \\
& B & Thellier & 50 & $250-550$ & 7 & 0.975 & 0.756 & $37.8 \pm 4.1$ & \\
YongQing & B & Shaw & 50 & $30-110$ & 6 & 0.999 & 0.928 & $46.5 \pm 1.2$ & \\
& A & Thellier & 50 & $250-550$ & 6 & 0.972 & 0.852 & $42.6 \pm 6.0$ & $3600 \pm 350$ \\
& A & Shaw & 50 & $20-100$ & 7 & 0.987 & 1.126 & $56.3 \pm 4.2$ & \\
& B & Thellier & 50 & $250-550$ & 6 & 0.993 & 0.914 & $45.6 \pm 2.0$ & \\
& C & Thellier & 50 & $250-550$ & 6 & 0.998 & 1.166 & $58.3 \pm 1.1$ & \\
& C & Shaw & 50 & $20-100$ & 7 & 0.999 & 1.322 & $66.1 \pm 1.3$ & \\
\hline
\end{tabular}

Note: $\mathrm{Bl}$ is the laboratory field used to create a TRM. The low and high.

Value are temperature $\left({ }^{\circ} \mathrm{C}\right)$ and alternating field $(\mathrm{mT})$ for the Thellier and the Shaw methods respectively.

\section{REFERENCES}

Aitken, M. J., A. L. Adrian, G. D. Bussell, and M. B. Winter, Geomagnetic intensity variation during the last 4000 years, Earth Planet. Inter., 56, 49-58, 1989.

Bullard, E. C., C. Freedman, H. Gellman, and J. Nixon, The westward drift of the Earth's magnetic field, Phil. Trans, Roy. Soc. London, A, 243, 67-92, 1950.

Coe, R. S., Paleo-intensities of the Earth's magnetic field determined from Tertiary and Quaternary rocks, $J$. Geophys. Res., 72, 3247-3262, 1967.

Day, R., M. Fuller, and V. A. Schmidt, Hysteresis properties of titanomagnetite: grain-size and compositional dependence, Phys. Earth Planet. Inter., 13, 260-267, 1977.

Fox, J. M. W. and M. J. Aitken, Cooling-rate dependence of thermoremanence magnetisation, Nature, 283, 462-463, 1980.

Mankinen, E. A. and D. E. Champion, Broad trends in geomagnetic paleointensity On Hawaii during Holocene time, J. Geophys. Res., 98, 7959-7976, 1993.

McElhinny, M. W. and W. E. Senanayake, Variations in the geomagnetic dipole 1: the past 50,000 years, J. Geomag. Geoelectr., 34, 39-51, 1982.

Rogers, J., J. M. W. Fox, and M. J. Aitken, Magnetic anisotropy in ancient pottery, Nature, 277, 644-646, 1979.

Rolph, T. C. and J. Shaw, A new method of palaeofield magnitude correction for thermally altered lavas and its application of Lower Carboniferous lavas, Geophys. J. R. Astron. Soc., 80, 773-781, 1985.

Senanayake, W. E. and M. W. McElhinny, Hysteresis and susceptibility characteristics of magnetite and titanomagnetites: interpretation of results from basaltic rocks, Phys. Earth Planet. Inter., 26, 47-55, 1981.

Shaw J., A new method of determining the magnitude of the palaeomagnitude field: application to five historic lavas and five archaeological samples, Geophys. J. R. Astron. Soc., 39, 133-141, 1974.

Stephenson, A., S. Sadikun, and D. K. Potter, A theoretical and experimental comparison of the anisotropies of magnetic susceptibility and remanence in rocks and minerals, Geophys. J. R. Astron. Soc., 84, 185-200, 1986.

Tanaka, H., Paleointensity high at 9000 years ago from volcanic rocks in Japan, J. Geophys. Res., 95, 17517-17531, 1990.

Tang, C., J. Y. Zheng, D. J. Li, S. F. Wei, and Q. Y. Wei, Palaeointensity determinations for the Xinjiang region, NW China, J. Geomag. Geoelectr., 43, 363-368, 1991.

Thellier, E. and O. Thellier, Sur l'intensitédu champ magnétique terrestre dans le passéhistorique et géologique, Ann. Géophys., 15, 285-376, 1959.

Wei, Q. Y., T. C. Li, G. Y. Chao, W. S. Chang, and S. P. Wang, Intensity of the geomagnetic field near Loyang, China, Between 500 B.C. and A.D. 1900, Nature, 292, 728-729, 1982.

Wei, Q. Y., D. J. Li, G. Y. Chao, W. X. Zhang, and S. F. Wei, The total intensity of the geomagnetic field in southern China for the period from 4500 B.C. to A.D. 1500, J. Geomag. Geoelectr., 38, 1311-1322, 1986.

Wei, Q. Y., W. X. Zhang, D. J. Li, M. J. Aitken, G. D. Bussell, and M. Winter, Geomagnetic intensity as evaluated from ancient Chinese pottery, Nature, 328, 330-333, 1987.

Yang, S., J. Shaw, and Q. Y. Wei, A comparison of archaeointensity results from Chinese ceramics using Thellier and Shaw's palaeointensity methods, Geophys. J. Int., 113, 499-508, 1993a.

Yang, S., J. Shaw, and Q. Y. Wei, Tracking a non-dipole geomagnetic anomaly using new archaeointensity results from northeast China, Geophys. J. Int., 115, 1189-1196, 1993b.

Yang, S., J. Shaw, and T. C. Rolph, Archaeointensity studies from Peruvian pottery-from $1200 \mathrm{BC}$ to $1800 \mathrm{AD}$, J. Geomag. Geoelectr., 45, 1193-1207, 1993c. 